\title{
Produtividade da soja em associação ao fungo micorrízico arbuscular Rhizophagus clarus cultivada em condições de campo
}

\author{
Production of soybean in association with the arbuscular mycorrhizal fungi Rhizophagus clarus \\ cultivated in field conditions
}
Thales Caetano de Oliveira', Hyuri Mendes Uehara', Luan Dionísio da Silva', Germanna Gouveia Tavares ${ }^{1}$, Letícia Rezende Santana1, Juliana Silva Rodrigues Cabral ${ }^{1}$, Edson Luiz Souchie ${ }^{1}$ e Giselle Camargo Mendes ${ }^{2 *}$

${ }^{1}$ Instituto Federal Goiano, Rio Verde, GO, Brasil.

${ }^{2}$ Instituto Federal Catarinense, Rio do Sul, SC, Brasil. *Autor para correspondência: giselle.mendes@ifc.edu.br.

Submissão: 29/03/2019 / Aceite: 01/07/2019

\begin{abstract}
RESUMO
A soja é fundamental para o progresso do agronegócio, porém sua produtividade pode ser afetada pelas mudanças climáticas. Assim, alternativas que aumentem o rendimento das plantas em condições adversas são fundamentais, e os fungos micorrízicos arbusculares (FMA) destacam-se, pois, associam-se as raízes das plantas aumentando a absorção de água e nutrientes. Assim, o objetivo deste trabalho foi avaliar a produtividade de plantas de soja a campo experimental em associação com o FMA Rhizophagus clarus sob condição de sistema irrigado e não irrigado. Ao final, avaliou-se parâmetros agronômicos e de simbiose com o FMA. O delineamento experimental foi em blocos casualizados com parcelas subdivididas, as médias obtidas foram submetidas à análise de variância e comparadas pelo teste Tukey (5\%), utilizando software SISVAR. Plantas de soja quando associadas com FMA e cultivadas em condição não irrigada, obtiveram maior produtividade do que plantas no sistema irrigado, além de peso de 1000 grãos. Desta forma, conclui-se que a inoculação beneficia a produtividade da soja em condições de sistema não irrigado.
\end{abstract}

PALAVRAS-CHAVE: produtividade de grãos, micorriza, colonização.

\begin{abstract}
Soybeans are key to agribusiness progress, but their production can be affected by climate change. Thus, alternatives that increase the yield of the plants under adverse conditions are fundamental, and the arbuscular mycorrhizal fungi (FMA) stand out. Therefore, they associate the roots of the plants, increasing the absorption of water and nutrients. Thus, the objective of this work was to evaluate soybean yield in the field experiment in association with FMA Rhizophagus clarus under conditions of irrigated and nonirrigated system. In the end, agronomic and symbiosis parameters were evaluated with FMA. The experimental design was in randomized blocks with subdivided plots, the means obtained were submitted to analysis of variance and compared by the Tukey test (5\%), using SISVAR software. Soybean plants when associated with FMA and cultivated in non-irrigated conditions, obtained higher productivity than plants in the irrigated system and weight of 1000 grains. In this way, it is concluded that inoculation benefits soybean yield under non-irrigated system conditions.
\end{abstract}

KEYWORDS: grain yield, mycorrhiza, colonization.

O sucesso das culturas depende das condições edafoclimáticas, em razão da sua instabilidade, o desenvolvimento e rendimento das plantas podem ser afetados (REICHERT et al. 2008). O déficit hídrico é um fator chave pela ocorrência de períodos maiores e mais longos de seca (EHTERAM et al. 2018). As respostas das plantas causadas pela restrição hídrica podem ser fisiológicas e bioquímicas, incluindo redução na eficiência fotossintética (SILVA et al. 2013).

Estes efeitos negativos ocasionado pelo déficit hídrico podem estimular a produção de espécies reativas de oxigênios (EROs), ocasionando a morte celular (CAVERZAN et al. 2016). Em condições de déficit hídrico a escolha da cultivar e o manejo da cultura são importantes, pois, a ocorrência deste estresse abiótico durante o ciclo de desenvolvimento, pode afetar diretamente a produtividade da cultura, por Rev. Ciênc. Agrovet., Lages, SC, Brasil (ISSN 2238-1171) 530 
exemplo, prejudicando o enchimento de grão (GAVA et al. 2015). Uma alternativa em potencial para as plantas, em situações propícias ao déficit hídrico é a utilização dos fungos micorrízicos arbusculares (FMA), que fazem simbiose com a maioria das plantas, proporcionando melhores condições de tolerar estresses abióticos (KHALVATI et al. 2010, ZOU et al. 2015).

Os benefícios dos FMA às plantas são múltiplos, visto que melhoram a absorção de nutrientes, principalmente em solos com baixa fertilidade (BERRUTI et al. 2016), proporcionando as plantas melhores condições de potencial hídrico e possibilitando responder positivamente aos efeitos adversos do déficit hídrico (HAMEED et al. 2015). Diante das perspectivas das mudanças climáticas e da possibilidade do déficit hídrico ser intensificado, estudos visando alternativas que beneficiem o desenvolvimento das plantas são fundamentais. Desta forma, o objetivo deste trabalho foi avaliar a produtividade da soja em associação ao FMA Rhizophagus clarus sob irrigação e condições naturais de campo.

O experimento foi conduzido na área experimental do Instituto Federal Goiano - Campus Rio Verde,

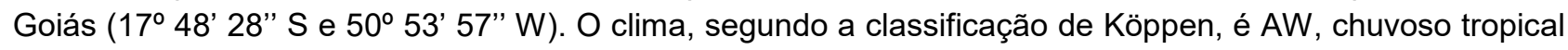
com inverno seco, temperatura média anual de 20-35 ำ. Durante o experimento, o índice pluviométrico foi de $947 \mathrm{~mm}$. O solo da área é classificado como Latossolo Vermelho distroférrico (LVdf) de textura média (EMBRAPA 2013). Sementes de soja (ANTA82), fornecidas pela empresa Uniggel Sementes foram inoculadas com bactérias fixadoras de nitrogênio (Bradyrhizobium japonicum), germinadas em 05/11/2017 e colhidas em 08/04/2018. A área do experimento foi de $351 \mathrm{~m}^{2}(39 \times 9 \mathrm{~m})$, cada parcela continha $16 \mathrm{~m}^{2}$ com oito linhas de plantio cada, o espaçamento foi de $0,50 \mathrm{~m}$ entre linhas e $0,055 \mathrm{~m}$ entre plantas, com 18 sementes por metro.

Para as parcelas irrigadas, utilizou-se o sistema de gotejamento, com tubos gotejadores (D1000 Rivulis) que eram ligados diariamente até atingir $80 \%$ da capacidade de campo do solo. A quantidade de água aplicada para o solo obter $80 \%$ da capacidade de campo (CC) foi determinada pela irrigação real necessária (IRN) e pela irrigação total necessária (ITN). Ao atingir o percentual requerido de CC, o manejo para irrigar as plantas diariamente foi calculado pela evapotranspiração, obtendo assim a lâmina bruta (LB) de irrigação por dia. Para as parcelas não irrigadas, a condução foi em circunstâncias naturais de campo para se assemelhar às condições dos produtores. O teor de água do solo na condição não irrigada foi obtido pelo balanço hídrico, seguindo os cálculos de acordo com THORNTHWAITE \& MATHER (1955). O balanço hídrico mostra o teor de água do solo durante o experimento no sistema irrigado e não-irrigado, com média de $80 \%$ de teor no sistema irrigado, enquanto que na condição não irrigada foi de $45 \%$ (Figura 1).

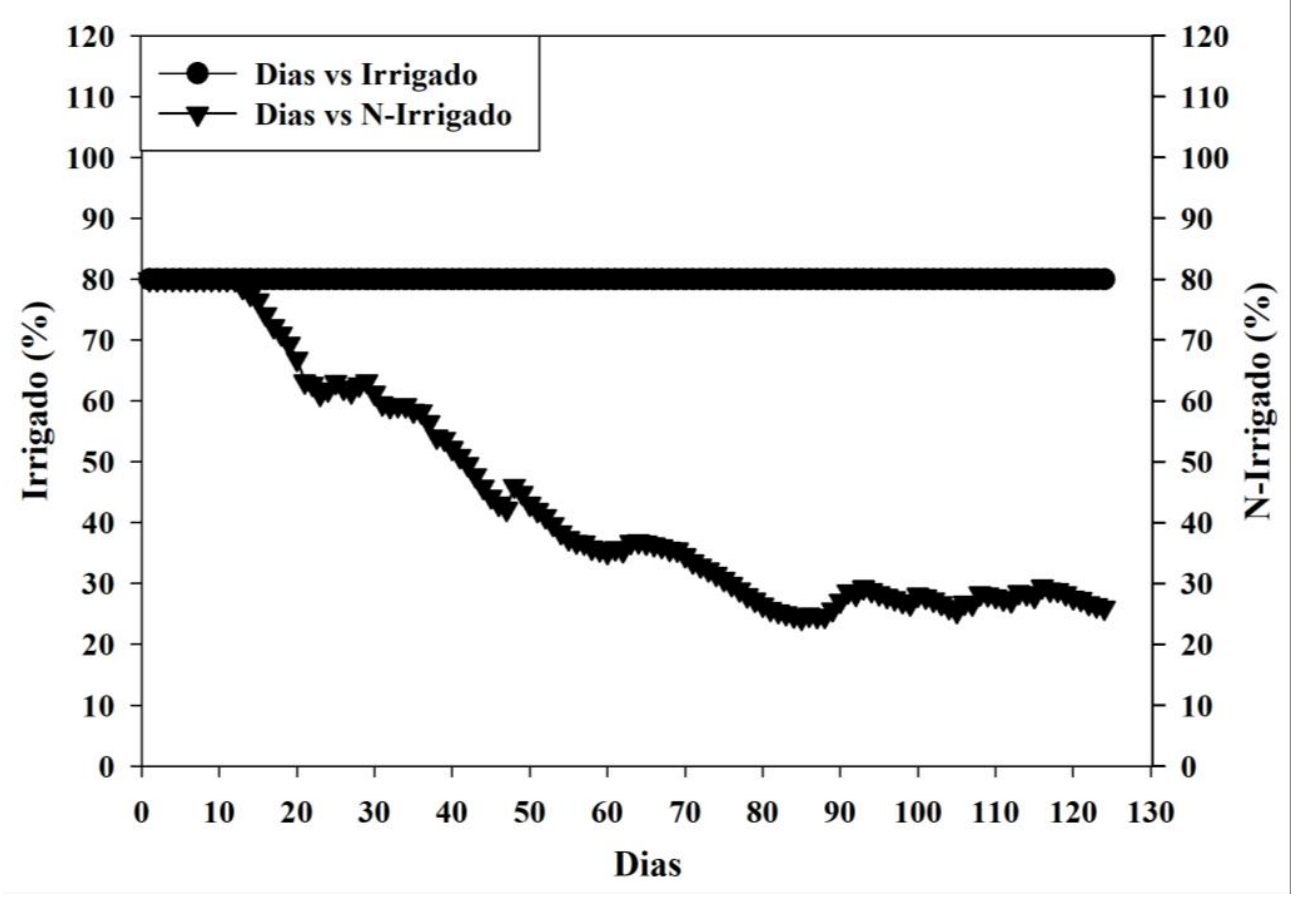

Figura 1. Teor de água no solo durante o ciclo de desenvolvimento da cultura, calculado pelo balanço hídrico. Irrigado = plantas sob condição de sistema irrigado, N-Irrigado = plantas sob condição de sistema não irrigado, Dias = quantidade de dias ocorridos na condução do experimento.

Figure 1. Water content in the soil during the crop development cycle, established by the water balance. Irrigated = plants under the condition of the irrigated system, $\mathrm{N}$-Irrigated = plants under condition of non-irrigated system, Days $=$ number of days occurred in the conduction of the experiment. 
O inoculante de FMA Rhizophagus clarus (=Glomus clarum, SCHÜßLER \& WALKER 2010) é procedente da coleção do Laboratório de Microbiologia do Solo da UNESP - Campus de llha Solteira, e foi doado ao IF Goiano - Campus Rio Verde. O tratamento com presença do inoculante Rhizophagus clarus foi inoculado com $10 \mathrm{~g}_{\text {do }} \mathrm{FMA}$ contendo 3,5 esporos $\mathrm{g}^{-1}$, em cada orifício de semeadura.

Para as avaliações, a bordadura tinha duas linhas de plantio sendo descartadas. Os parâmetros mensurados foram: altura de inserção da primeira vagem, número de vagens, número de grãos por planta, peso de 1000 grãos, densidade de esporos de acordo com GERDEMANN \& NICHOLSON (1963) e colonização micorrízica, em que as raízes foram despigmentadas de acordo com KOSKE \& GEMMA (1989) modificado e coradas de acordo com PHILLIPS \& HAYMAN (1970). Para estes, foram avaliadas cinco plantas em todas as parcelas de cada tratamento. Além disso, foi determinado a produtividade (fórmula: peso das sementes $(\mathrm{kg}) \times$ área em hectare $\left(10000 \mathrm{~m}^{2}\right) /$ área de colheita $\left.\left(12 \mathrm{~m}^{2}\right)\right)$, sendo que do valor total obtido, também foi calculado o número de sacas por hectare.

$O$ experimento foi conduzido em delineamento de blocos casualizados com parcelas subdivididas (sistema irrigado e não irrigado), com os tratamentos: 1) Plantas na ausência do FMA sob condições de sistema irrigado; 2) Plantas em ausência do FMA sob condições de sistema não irrigado; 3) Plantas inoculadas com o FMA sob condições de sistema irrigado e 4) Plantas inoculadas com o FMA sob condições de sistema não irrigado. Os dados foram submetidos à análise de variância e as médias, comparadas pelo teste Tukey (5\%), utilizando o software SISVAR.

De acordo com os resultados observados nas Figuras $2 \mathrm{~A}, \mathrm{~B}$ e C, a altura da primeira vagem, número de vagens e de sementes por planta não diferiram entre os tratamentos sob condição de sistema irrigado e não irrigado, assim como, quando se compara plantas inoculadas e não inoculadas. Para a produtividade não houve diferença entre as plantas com e sem inoculação sob condição irrigada e não irrigada (Figura 2 D). Porém, as plantas de soja na presença do inoculante Rhizophagus clarus produziu em condição não irrigado $4,151 \mathrm{~kg} / \mathrm{ha}$, e plantas em sistema não irrigado produziu $3,608 \mathrm{~kg} / \mathrm{ha}$. Em plantas com ausência de inoculação não houve diferenças entre o sistema irrigado e não irrigado. $O$ resultado da produtividade em número de sacas por hectare, para plantas na presença do FMA cultivadas em sistema não irrigado foi de 69 sacas/hectare, valor maior que o obtido por plantas em sistema irrigado (60 sacas/hectare).

Para a variável peso de 1000 grãos, as plantas não irrigadas tiveram peso significativamente superior quando comparadas com as plantas irrigadas (Figura 3).

A densidade de esporos no solo nas plantas cultivadas em condição de irrigação e inoculação foi superior às plantas sem inoculação (Figura 4 A). Situação que ocorreu para a condição de não irrigação, cujo valor das plantas inoculadas foi maior que sem inoculação. $O$ tratamento inoculado foi significativamente superior nas plantas não irrigadas em comparação as plantas irrigadas. Para o tratamento sem inoculação, as plantas não irrigadas apresentaram valor maior em comparação com plantas irrigadas.

O percentual de colonização micorrízica (Figura 4 B) em plantas irrigadas e inoculadas alcançou o valor de $18 \%$, superando as plantas sem inoculação (10\%). A mesma situação ocorreu para a condição de não irrigação, tendo as plantas inoculadas maior percentual em comparação com as sem inoculação. Os tratamentos de presença e ausência do inoculante de FMA em condições de irrigação e não irrigação não tiveram diferença significativa.

Observou-se, pela colheita, a importância dos fungos micorrízicos para a produção das plantas, pois a inoculação do Rhizophagus clarus proporcionou as plantas, mesmo em condição não irrigada, uma maior produtividade (4.151 kg/ha) (Figura $2 \mathrm{D})$, quando comparadas as plantas inoculadas sob condição de sistema não irrigado (3.608 kg/ha), destacando a contribuição dos FMA para as plantas de soja. Em condição de déficit hídrico, as plantas liberam exudados para as raízes, no qual estes irão induzir a germinação dos esporos. Por conseguinte, hifas serão formadas e penetrarão as raízes, estabelecendo uma simbiose, ajudando no desenvolvimento vegetal em situação de déficit hídrico. As hifas podem conferir as plantas maior sistema radicular, com aumento da absorção de água e, consequentemente, a manutenção da condutância estomática, ou seja, os estômatos ficaram abertos e em decorrência disto, a absorção de $\mathrm{CO}_{2}$ aumenta. Isto representa maior potencial de fixação de $\mathrm{CO}_{2}$ e produção de fotoassimilados, sendo estes, a fonte de alimentação da planta. A produtividade obtida, de acordo com a CONAB (2018), ficou acima da média nacional (3.359 kg/ha) na safra 2017/2018.

A importância dos fungos micorrízicos para as plantas em condições naturais de campo pode ser destacada pelos resultados obtidos por FUGANTI-PAGLIARINI et al. (2017) que, ao trabalharem com ausência de inoculação de FMA, observaram que as cultivares BR 16, 1 Ab58 e 1Bb2193 de soja, cultivadas em condição natural de campo, tiveram rendimento produtivo abaixo dos $2.000 \mathrm{~kg} / \mathrm{ha}$, menor que as plantas 
sob condição de irrigação, que ficou acima dos $2.500 \mathrm{~kg} / \mathrm{ha}$. Em condições de boa irrigação, as plantas encontram-se em plena condição para desempenhar o processo fotossintético. Sendo assim, não irão sinalizar através da liberação de exsudados, não favorecendo a germinação dos esporos e com isto não ocorrerendo simbiose entre as plantas e FMA. O benefício dos FMA para a maior produtividade das plantas em condição não irrigada está associado ao conteúdo de esporos no solo (Figura 4 A) e colonização micorrízica (Figura 4 B).
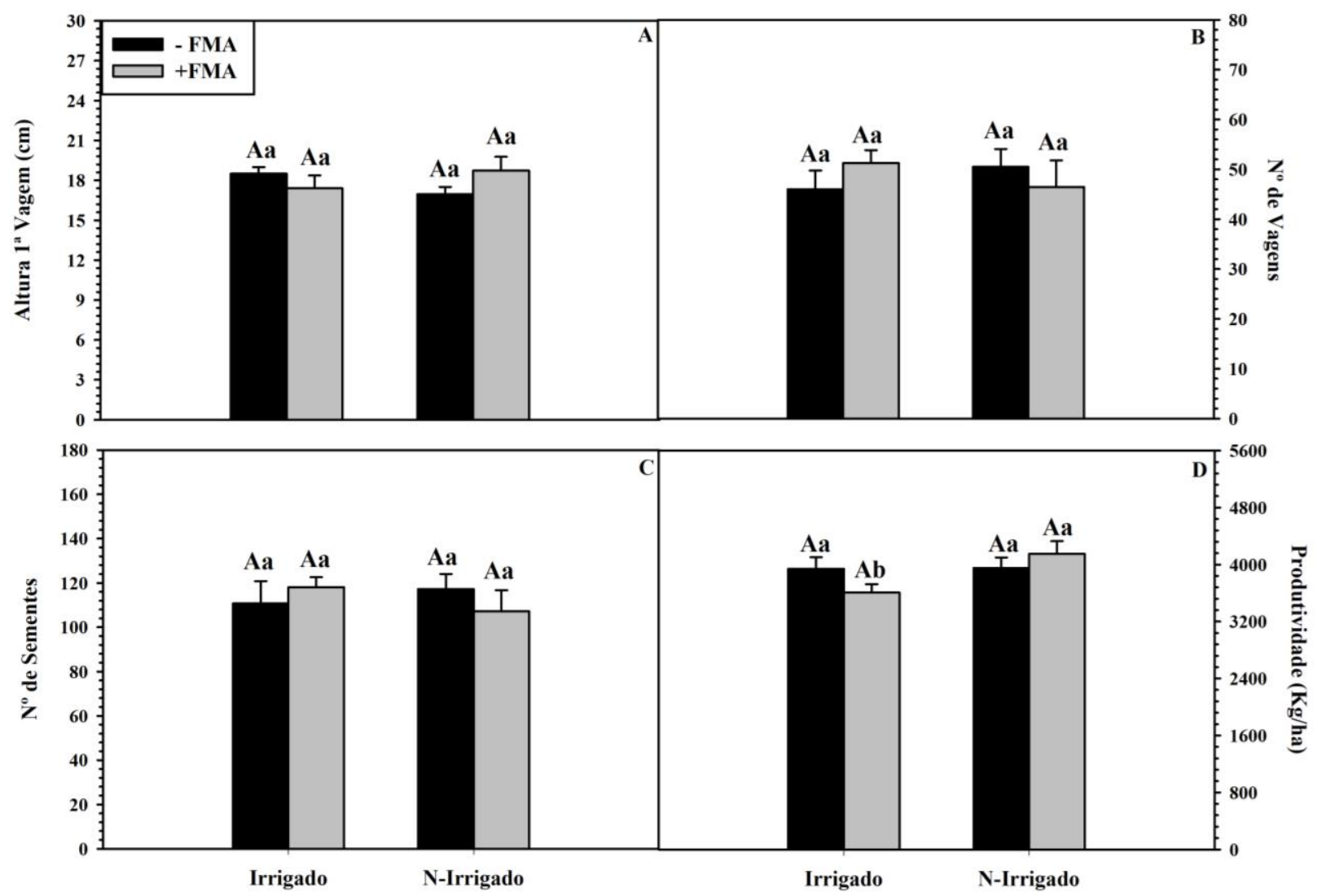

Figura 2. Altura da $1^{\text {a }}$ vagem $(A)$, número de vagens $(B)$, número de sementes $(C)$ e produtividade $(D)$ em plantas de soja com e sem inoculação do FMA Rhizophagus clarus em condições de sistema irrigado e não irrigado. Irrigado = plantas sob condição de sistema irrigado, $\mathrm{N}$-Irrigado = plantas sob condição de sistema não irrigado, $-\mathrm{FMA}=$ plantas não inoculadas, $+\mathrm{FMA}=$ plantas inoculadas. Médias seguidas pela mesma letra não diferem entre si pelo teste Tukey $(5 \%)$. Letras maiúsculas indicam diferenças significativas entre os tratamentos com e sem inoculação do FMA; letras minúsculas indicam diferenças significativas entre os sistemas irrigado e não-irrigado.

Figure 2. Height of $1^{\text {st }}$ pod $(A)$, number of pods $(B)$, number of seeds, $(C)$ and yield $(D)$ in soybean plants with and without inoculation of FMA "Rhizophagus clarus" under irrigated and non-irrigated system conditions. Irrigated = plants under irrigation condition, $N$-Irrigated $=$ plants under condition of nonirrigated system, $-F M A=$ uninoculated plants, $+F M A=$ inoculated plants. Means followed by the same letter do not differ by the Tukey test (5\%). Different uppercase letters following values indicate significant differences between treatments with and without inoculation of FMA, different lowercase letters following values indicate significant differences between irrigated and nonirrigated systems.

Observou-se maior percentual de colonização nas plantas inoculadas que nas plantas sem inoculação (Figura 4 B). Este resultado se assemelha aos resultados de BARROS et al. (2018), que ao observarem plantas de Cynophala flexuosa sem inoculação não obtiveram colonização micorrízica, enquanto plantas inoculadas com Claroideoglomus etunicatum (=Glomus etunicatum, SCHÜßLER \& WALKER 2010) e Acaulospora longula, obtiveram o mesmo percentual de colonização. Nota-se que o FMA induziu aumento de produtividade em plantas de soja inoculadas em condição de sistema não irrigado, que foi maior que nas plantas inoculadas em sistema irrigado. Segundo MATHUR et al. (2018), a colonização micorrízica pode aumentar o crescimento das plantas e diminuir efeitos negativos de estresses como o déficit hídrico, pela indução do crescimento das hifas, que penetram nas raízes, formando uma extensão. 


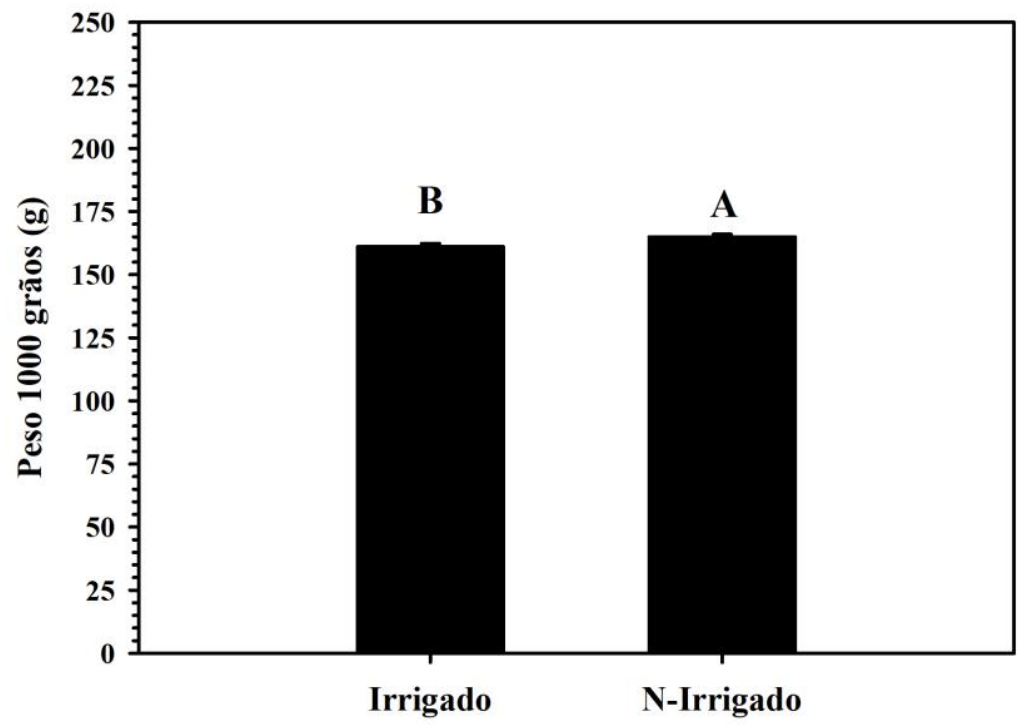

Figura 3. Peso de 1000 grãos (F) em plantas de soja com e sem inoculação do FMA Rhizophagus clarus em condições de sistema irrigado e não irrigado. Irrigado = plantas sob condição de sistema irrigado, $\mathrm{N}$-Irrigado = plantas sob condição de sistema não irrigado. Médias seguidas pela mesma letra não diferem entre si pelo teste Tukey (5\%).

Figure 3. 1000 grain weight $(F)$ in soybean plants with and without FMA "Rhizophagus clarus" inoculation under irrigated and non-irrigated system conditions. Irrigated = plants under irrigation condition, $\mathrm{N}$ Irrigated = plants under the condition of non-irrigated system. Means followed by the same letter do not differ by Tukey test (5\%).

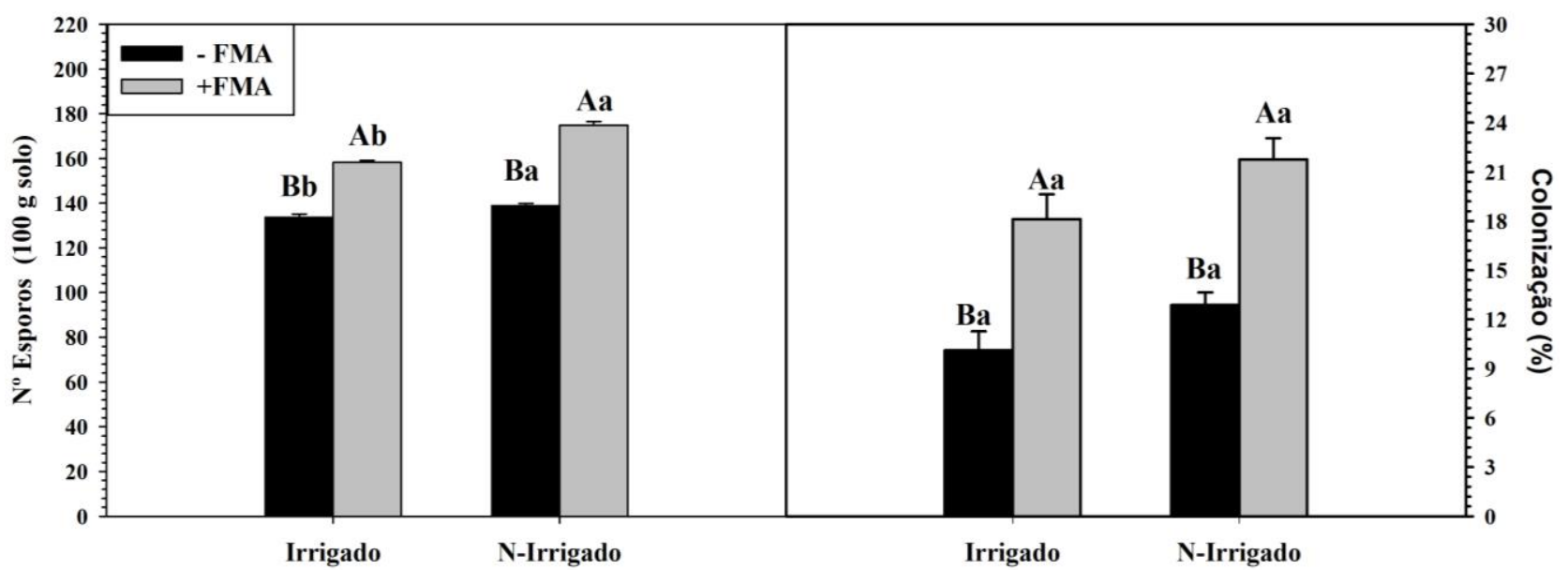

Figura 4. Número de esporos em $100 \mathrm{~g}$ de solo (A), percentual de colonização micorrízica (B) em plantas de soja com e sem inoculação do FMA Rhizophagus clarus em condições de sistema irrigado e não irrigado. Irrigado = plantas sob condição de sistema irrigado, $\mathrm{N}$-Irrigado = plantas sob condição de sistema não irrigado, $-\mathrm{FMA}=$ plantas não inoculadas, $+\mathrm{FMA}=$ plantas inoculadas. Médias seguidas pela mesma letra não diferem entre si pelo teste Tukey (5\%). Letras maiúsculas indicam diferenças significativas entre os tratamentos de com e sem inoculação do FMA, letras minúsculas diferentes seguindo os valores indicam diferenças significativas entre os sistemas irrigado e não-irrigado.

Figure 4. Number of spores in $100 \mathrm{~g}$ of soil (A), percentage of mycorrhizal colonization (B) in soybean plants with and without inoculation of "Rhizophagus clarus" FMA under irrigated and non-irrigated system conditions. Irrigated = plants under irrigation condition, $N$-Irrigated = plants under condition of nonirrigated system, $-F M A=$ uninoculated plants, $+F M A=$ inoculated plants. Means followed by the same letter do not differ by the Tukey test (5\%). Different uppercase letters following values indicate significant differences between treatments with and without inoculation of FMA, different lowercase letters following values indicate significant differences between irrigated and non-irrigated systems. 
A inoculação do FMA Rhizophagus clarus propiciou que as plantas de soja cultivadas em campo sob condição não irrigada tivessem maior produtividade do que as plantas inoculadas em sistema irrigado. A simbiose com o FMA aumentou o rendimento das plantas a campo na ausência de irrigação.

\section{AGRADECIMENTO}

Agradecemos à CAPES pela concessão de bolsa de mestrado ao primeiro autor, ao campus Rio Verde do Instituto Federal Goiano, pela infraestrutura, e ao CNPq pelo projeto universal aprovado no edital universal 01-2016, processo número 406197/2016-4.

\section{REFERÊNCIAS}

BARROS $V$ et al. 2018. Arbuscular mycorrhizal fungi improve photosynthetic energy use efficiency and decrease foliar construction cost under recurrent drought stress in woody evergreen species. Plant Physiology and Biochemistry 127: 469-477.

BERRUTI A et al. 2016. Arbuscular mycorrhizal fungi as natural biofertilizers: let's benefit from past successes. Frontiers Microbiology 6: 1-13.

CAVERZAN A et al. 2016. Reactive oxygen species and antioxidant enzymes involved in plant tolerance to stress. In: SHANKER AK \& SHANKER C. Abiotic and biotic stress in plants - Recent advances and future perspectives. Publisher InTech: 463-480.

CONAB. 2018. Companhia Nacional de Abastecimento. Acompanhamento da safra brasileira de grãos: 9o levantamento grãos safra 2017/18. Disponível em: <https://www.conab.gov.br/info-agro/safras/graos>. Acesso em: 25 jun. 2018.

EHTERAM M et al. 2018. Reservoir operation based on evolutionary algorithms and multi-criteria decision-making under climate change and uncertainty. Journal of Hydroinformatics 20: 332-355.

EMBRAPA. 2013. Empresa Brasileira de Pesquisa Agropecuária. Sistema Brasileiro de Classificação de Solos. 3.ed. Brasília: Embrapa. 353p.

FUGANTI-PAGLIARINI R et al. 2017. Characterization of soybean genetically modified for drought tolerance in field conditions. Frontiers in Plant Science 8: 1-15.

GAVA R et al. 2015. Estresse hídrico em diferentes fases da cultura da soja. Revista Brasileira de Agricultura Irrigada 9: 349-359.

GERDEMANN JW \& NICHOLSON TH. 1963. Spores of mycorhizal Endogone species extracted from soil by wet sieving and decanting. Transactions of the British Mycological Society 46: 235-244.

HAMEED A et al. 2015. Role of AM fungi in alleviating drought stress in plants. In: MIRANSARI M. (Ed.). Use of microbes for the alleviation of soil stresse. New York: Springer. p.55-75.

KHALVATI M et al. 2010. Arbuscular mycorrhizal association is beneficial for growth and detoxification of xenobiotics of barley under drought stress. Journal of Soils and Sediments 10: 54-64.

KOSKE RE \& GEMMA JN. 1989. A modified procedure for staining roots to detect VA mycorrhizas. Mycological Research 92: 486-505.

MATHUR S et al. 2018. Improved photosynthetic efficacy of maize (Zea mays) plants with Arbuscular mycorrhizal fungi (AMF) under high temperature stress. Journal of Photochemistry and Photobiology 180: 149-154.

PHILLIPS JM \& HAYMAN DS. 1970. Improved procedures for clearing roots and staining parasitic and vesiculararbuscular mycorrhyzal fungi for rapid assessment of infection. Transactions of the British Mycological Society 55: 158161.

REICHERT JM et al. 2008. Variabilidade espacial de Planossolo e produtividade de soja em várzea sistematizada: análise geoestatística e análise de regressão. Ciência Rural 38: 981-988.

SCHÜßLER A \& WALKER C. 2010. The Glomeromycota. A Species List with New Families and New Genera. Libraries at The Royal Botanic Garden Edinburgh, The Royal Botanic Garden Kew, Botanische Staatssammlung Munich and Oregon State University. 56p.

SILVA MA et al. 2013. Photosynthetic capacity and water use efficiency in sugarcane genotypes subject to drought stress during early growth phase. Brazilian archives of biology and technology 56: 735-748.

THORNTHWAITE CW \& MATHER JR. 1955. The water balance. Centerton: Drexel Institute of Technology. 104p. (Publications in Climatology VIII)

ZOU YN et al. 2015. Mycorrhiza-induced lower oxidative burst is related with higher antioxidant enzyme activities, net H2O2 effluxes, and Ca2+ influxes in trifoliate orange roots under drought stress. Mycorrhiza 25: 143-152. 